\title{
Relationship Between Intestinal Gas and the Development of Right Colonic Diverticula
}

\author{
Sung-IIl Jang, $M D^{1}$, Jie-Hyun Kim, $M D^{1}$, Young Hoon Youn, MD ${ }^{1}$, Hyojin Park, MD, PhD ${ }^{1 *}$, Sang In Lee, MD ${ }^{1}$ and \\ Jeffrey L Conklin ${ }^{2}$ \\ ${ }^{1}$ Department of Internal Medicine, Yonsei University College of Medicine, Seoul, Korea, ${ }^{2}$ Division of Gastroenterology, Cedars-Sinai Medical \\ Center, Los Angeles, California, USA
}

\begin{abstract}
Backgrounds/Aims
High intraluminal pressure has been reported to cause left colonic diverticula. However, the pathophysiology of right colonic diverticula is still unclear. Methane gas has been reported to delay small intestinal transit and to increase intraluminal pressure. The aim of this study was to evaluate the relationship between right colonic diverticula and intestinal gas produced by enteric bacteria.
\end{abstract}

\section{Methods}

Lactulose breath tests were performed in 30 patients who were diagnosed with right colonic diverticula via colonoscopy. The control group consisted of 30 healthy adults with no specific symptoms or medical histories. A hydrogen or methane producer was defined in 2 ways: either one that exhibited a breath hydrogen level $\geq 20 \mathrm{ppm}$ (methane $\geq 10 \mathrm{ppm}$ ) baseline or one that exhibited an increase in breath hydrogen $\geq 20$ ppm (methane $\geq 10 \mathrm{ppm}$ ) above baseline within the first 90 minutes of the test.

\section{Results}

The lactulose breath test (LBT) positivity in the diverticular group and the control group were $40.0 \%$ and $33.3 \%$, respectively, without a statistically significant difference. The concentrations of methane and hydrogen gas measured by LBT increased over time, but there was no significant difference between the control and the diverticular groups.

\section{Conclusions}

There was no significant relationship between right colonic diverticula and intestinal gases produced by enteric bacteria. However, time-dependent formation of diverticula should be taken into consideration, therefore long-term, large-scale follow-up studies may reveal further pathogenesis of right colonic diverticulosis.

\section{(J Neurogastroenterol Motil 2010;16:418-423)}

Key Words

Diverticulum, colon; Hydrogen; Methane

Received: October 4, 2010 Revised: October 8, 2010 Accepted: October 10, 2010

(c) This is an Open Access article distributed under the terms of the Creative Commons Attribution Non-Commercial License (http://creativecommons. org/licenses/by-nc/3.0) which permits unrestricted non-commercial use, distribution, and reproduction in any medium, provided the original work is properly cited.

*Correspondence: Hyojin Park, MD, PhD Department of Internal Medicine, Gangnam Severance Hospital, Yonsei University College of Medicine, 712 Eonju-ro, Gangnamgu, Seoul 135-720, Korea

Financial support: None.

Tel: +82-2-2019-3318, Fax: +82-2-3463-3882, E-mail: HJPARK21@yuhs.ac

Conflicts of interest: None. 


\section{Introduction}

Colonic diverticulosis is an acquired disease that results from herniation of the mucosal and submucosal layers through defects in the muscle layer. The exact prevalence of diverticulosis is difficult to estimate because most individuals are asymptomatic, but the disease is endemic in elderly populations of developed countries. ${ }^{1}$ There is a considerable geographic variation between Asian and Western countries with regard to the prevalence and pathophysiology of diverticular disease. ${ }^{2}$ In Western countries, diverticula are most common in the left colon, including the descending and sigmoid colon. In Asian countries, diverticula occur primarily in the right colon, such as the cecum and ascending colon. This epidemiological difference suggests that genetic, environmental and/or lifestyle factors play a role in the etiology of colonic diverticula. ${ }^{3}$ Over the last several decades, researchers have evaluated different pathophysiological causes of colonic diverticulosis using epidemiological as well as basic research. The pathogenesis of colonic diverticula has multiple factors, including age-associated alterations in the colonic wall, ${ }^{2,4,5}$ dietary fiber intake, ${ }^{3,6-8}$ motor dysfunction, ${ }^{9}$ genetic influences, ${ }^{3,10,11}$ altered colonic motility $^{12}$ and abnormal intraluminal pressure. ${ }^{13}$

The most widely accepted theory on the role of dietary fiber in diverticular formation is that smaller-volume stool results in alterations in colonic motility that result in increased intraluminal pressure. ${ }^{14}$ Increased intraluminal pressure is attributed to segmental movement of the colon. ${ }^{15}$ In those who eat low-fiber diets, this normal physiologic process becomes exaggerated, thereby generating markedly elevated intrasegmental colonic pressures. ${ }^{13}$ The straining and high amplitude, non-propulsive contractions that lead to high intraluminal pressure have been known to cause the formation of left colonic diverticula.

Some epidemiological studies have suggested that a genetic predisposition exists for the formation of right colonic diverticula because it develops at an earlier age than does left-sided diverticula $^{16-18}$ and is the dominant form of diverticulitis in a studied Japanese Hawaiian community whose members emigrated from Asia. ${ }^{19}$ However, the pathophysiology of right colonic diverticula is still unclear.

Colonic diverticulosis patients were found to have increased methanogen concentrations based on direct fecal counts. ${ }^{20}$ More recently, methane gas and its relationship with intestinal transit time have been assessed. ${ }^{21}$ Our group also reported that the peristaltic velocity of the small bowel was significantly delayed after methane gas infusion into guinea pigs. ${ }^{22}$ The amplitudes of peristaltic colonic contractions and intraluminal pressures were also significantly increased in the group treated with methane gas infusion. One study that included 2 experiments supports the theory that methane is involved in the regulation of intestinal motor function. ${ }^{23}$ Methane gas creates a slowing of intestinal transit in dogs, and the contractile activity of guinea pig ileum is significantly augmented when exposed to methane gas. It was hypothesized that methane slows small intestinal contractile activity by augmenting small-bowel contractile activity, possibly through non-propulsive segmental contractions. This process suggests that methane augments the amplitudes of peristaltic waves in the small bowel and delays small bowel transit because it promotes non-propagating or segmental contractions, which provided an experimental basis for verifying that a significant correlation exists between methane producers and constipation-predominant irritable bowel syndrome (IBS) patients.

The lactulose breath test (LBT) is a test that measures the concentrations of exhaled methane and hydrogen gas after ingestion of lactulose. We hypothesized that the methane gas produced by enteric bacteria may have a role in the development of right colonic diverticula by propagating non-propulsive segmental contraction, which leads to increased intraluminal pressure and accelerates the formation of diverticula in the right colon. The goal of our present study was to use LBT to investigate the relationship between the development of right colonic diverticula and intestinal gases produced by enteric bacteria.

\section{Materials and Methods}

\section{Patients and controls}

The study was conducted on consecutive patients at the outpatient clinic of the gastroenterology division of Gangnam Severance Hospital of Yonsei University, Korea, between February 2008 and February 2010. Right colonic diverticula were evaluated via full colonoscopy in all patients. The normal volunteer population consisted of 30 healthy volunteers with no specific symptoms or medical history.

Patients with diverticula were placed into the diverticular group, and normal controls were classified as our control group. All participants in both groups were referred for LBT and were personally interviewed by the investigators. Prior to conducting the breath test, participants were given a questionnaire that assessed their past medical histories, current medication usages, 
demographic information and 7 main symptoms (abdominal pain, bloating, constipation, diarrhea, flatulence, tenesmus and early satiety) of IBS. The severity and frequency of the symptoms were expressed by ordinal scales from 0 to 6 on a Likert Scale. Exclusion criteria were age below 18 or above 80 years, having known organic intestinal disease, prior abdominal surgery, unstable thyroid disease or diabetes, using motility-modifying medication (such as prokinetics, narcotics, calcium channel blockers or anticholinergics) and use of antibiotics within the past month, or being pregnant. In addition, subjects completed a questionnaire of Rome II criteria for IBS. This study was approved by the Institutional Review Board at Gangnam Severance Hospital, and all participants were enrolled under informed written consent for participation (IRB No. 3-2010-0117).

\section{Lactulose breath test}

LBT were performed following an overnight fast of at least 12 hours. Participants were asked to not ingest any beans, nuts, soy or large meals, to limit dairy intake the day before the test, and to refrain from smoking the morning of the test. After a sample of their breath (end expiratory) was collected at baseline, participants ingested $10 \mathrm{~g}$ lactulose syrup (Choongwae Pharma Co, Seoul, Korea) with $240 \mathrm{~mL}$ water. Further breath samples were then obtained every 15 minutes for 180 minutes. Each sample was analyzed for hydrogen, methane and carbon dioxide gas concentrations within 15 minutes of collection using a Quintron model SC gas chromatograph (Quintron Instrument Co, Milwaukee, WI, USA). Data were reported in parts per million (ppm). Carbon dioxide was analyzed to correct for the quality of alveolar sampling. The measurements were then plotted graphically and analyzed by a trained technician. LBT results were interpreted by an experienced clinician who was blinded to participant conditions and symptoms. A hydrogen producer was defined in 2 ways: either one who exhibited a breath hydrogen level $\geq 20 \mathrm{ppm}$ at baseline or one who exhibited an increase in breath hydrogen $\geq 20$ ppm above baseline within the first 90 minutes of the test. A positive methane breath test was defined in 2 ways: either one who exhibited a breath methane level $\geq 10 \mathrm{ppm}$ at baseline or one who exhibited an increase in breath hydrogen $\geq$ 10 ppm above baseline within the first 90 minutes of the test. A combined producer was defined as one who was positive for both methane and hydrogen production. ${ }^{22}$

\section{Statistical methods}

Quantitative data were compared using Student's $t$ test, with results expressed as mean $\pm \mathrm{SD}$. We used the Chi-square test and Fisher's exact test to assess differences between patients with diverticula and controls. Comparisons between breath methane and hydrogen concentrations at each time point were made using linear mix model. Data were analyzed (PASW version 17.0) and pictorially illustrated using GraphPad Prism version 4 (GraphPad Software Inc, San Diego, CA, USA). A p-value less than 0.05 was considered statistically significant.

\section{Results}

A total of 60 people participated in this study (30 in the diverticular group and 30 in the control group). The 2 groups had no statistical difference in their demographic characteristics (Table 1).

Forty percent of the diverticular group was LBT-positive compared with $30 \%$ of the control group. LBT positivity did not show a significant difference between the diverticular and the control group $(p=0.4)$. Methane production was found in $20 \%$ of the diverticular group and in $23.3 \%$ of the control group. No statistically significant association existed between methane production and diverticula $\left(\chi^{2}=0.1, \mathrm{p}=0.8\right)$. Hydrogen production and diverticula also did not have a statistically significant association $\left(\chi^{2}=0.3, \mathrm{p}=0.7\right)$ (Table 1$)$. And there was no difference in irritable bowel symptom between the patients with positive LBT and others with negative LBT within the diverticular group (Table 2).

The diverticular and the control group demonstrated similar breath methane excretion patterns over time (Fig. 1A); no statistically significant differences existed at any time point for breath methane excretion. This pattern was also seen for breath hydrogen excretion (Fig. 1B). And the proportion of breath methane to

Table 1. Comparison of Demographic Findings and Lactulose Breath Test Results Between the Diverticular and the Control Groups

\begin{tabular}{lccl}
\hline \multicolumn{1}{c}{ Parameters } & $\begin{array}{c}\text { Control group } \\
(\mathrm{n}=30)\end{array}$ & $\begin{array}{c}\text { Diverticular group } \\
(\mathrm{n}=30)\end{array}$ & $\mathrm{p}$-value \\
\hline Age (mean $\pm \mathrm{SD})$ & $47.4 \pm 14.1$ & $53.3 \pm 9.9$ & $0.07^{\mathrm{a}}$ \\
Males $(\%)$ & 60.0 & 63.3 & 0.9 \\
LBT $(\%)$ & 30.0 & 40.0 & $0.4^{\mathrm{b}}$ \\
Methane producer & 23.3 & 20.0 & 0.8 \\
Hydrogen producer & 3.4 & 20.0 & 0.7 \\
Combined producer & 3.3 & 0.0 & 0.6 \\
\hline
\end{tabular}

${ }^{\mathrm{a}}$ Student's $t$ test for difference of means, ${ }^{\mathrm{b}} \mathrm{Chi}$-square test or Fisher's test for differences of proportion. 
A

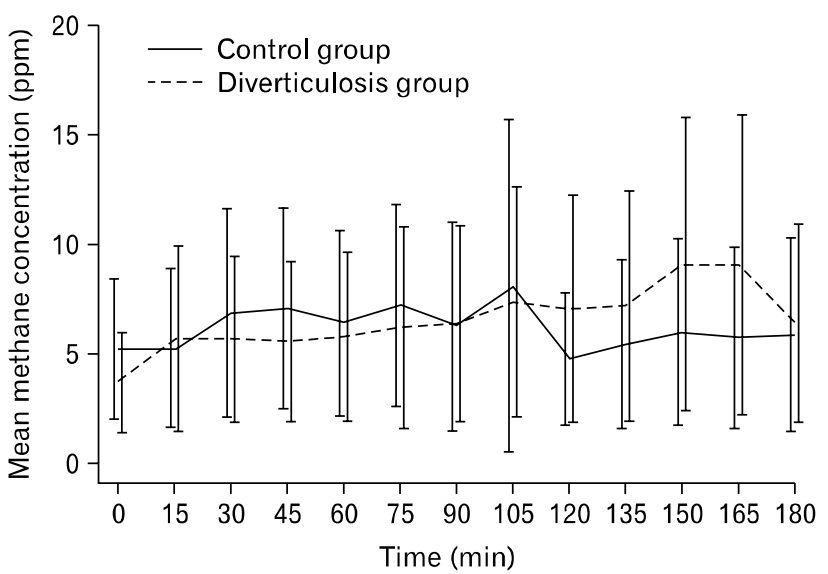

B

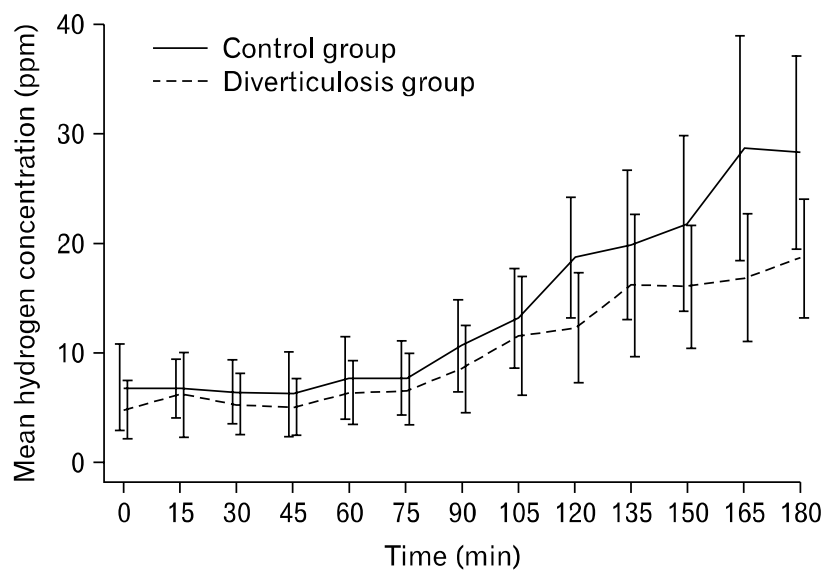

Figure 1. Comparison of breath methane and hydrogen concentrations over time between the diverticular group (solid line) and the control group (dashed line). The breath methane and hydrogen concentration was presented with mean $\pm \mathrm{SD}$ at each time point and analysed using linear mix model. There was no statistically significant difference between the diverticular and control groups in breath methane (A) and hydrogen (B) concentration.

Table 2. Comparison of Bowel Symptoms and Lactulose Breath Test Results in the Diverticular Group

\begin{tabular}{lccc}
\hline \multirow{2}{*}{ Parameters } & \multicolumn{2}{c}{ LBT $(\mathrm{N}=30)$} & \\
\cline { 2 - 3 } & Positive $(\mathrm{n}=12)$ & Negative $(\mathrm{n}=18)$ & \\
\hline Symptom score $^{\mathrm{b}}$ & & & \\
$\quad$ Abdominal pain & $4.6 \pm 3.1$ & $4.2 \pm 3.2$ & 0.9 \\
Constipation & $1.7 \pm 2.5$ & $2.3 \pm 2.7$ & 0.5 \\
Diarrhea & $3.6 \pm 2.8$ & $3.3 \pm 3.3$ & 0.8 \\
Tenesmus & $4.3 \pm 3.3$ & $3.7 \pm 3.7$ & 0.7 \\
Bloating & $4.8 \pm 2.5$ & $3.8 \pm 4.0$ & 0.4 \\
Flatulence & $5.8 \pm 2.8$ & $5.7 \pm 3.8$ & 0.9 \\
Early satiety & $3.2 \pm 2.4$ & $2.9 \pm 3.5$ & 0.8 \\
\hline
\end{tabular}

${ }^{\mathrm{a}}$ Student's $t$ test for difference of means, ${ }^{\mathrm{b}} \mathrm{Mean} \pm \mathrm{SD}$.

hydrogen concentration was greater in diverticular group than in control group after 80 minutes but no statistical difference was not found (Fig. 2).

\section{Discussion}

The present study showed that LBT positivity did not present a significant difference between the diverticular group and the control group, which meant the detection of methane or hydrogen based on LBT is not associated with right colonic diverticula. Although there was no significant relation between development of right diverticula and intestinal gas, this study is first attempt to reveal the pathogenesis of right diverticula.

Many studies have shown that increased concentration of

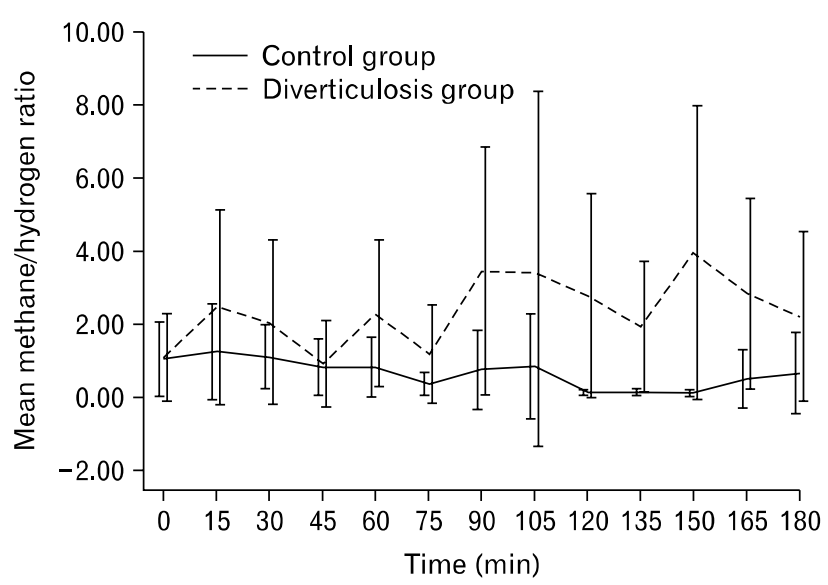

Figure 2. Comparison of breath methane/hydrogen concentrations ratio over time between the diverticular group (solid line) and the control group (dashed line). The proportion of breath methane to hydrogen concentration was higher in diverticular group than in control group after 80 minutes but statistically significant difference between the diverticular and control groups was not found.

methane delays colonic transit time. Methane production is more common in constipated conditions, such as encopresis and diverticulosis, and is much less frequent in predominantly diarrheal conditions such as inflammatory bowel disease ${ }^{20,24-28}$ Two studies have demonstrated slower transit times in methane-producing adults. ${ }^{4,29}$ The first measured mouth-to-cecum transit times of healthy participants using the lactulose hydrogen breath test. These researchers found that breath methane producers had a significantly longer transit time (111 minutes) compared to their 
non-producing counterparts (68 minutes). ${ }^{29}$ In the second study, whole gut transit was evaluated. They found that breath methane producers had a mean transit time of 84.6 hours versus the 48.6 hours demonstrated by non-producers. ${ }^{4}$ Evidence has accumulated to support an association between methane and intestinal transit time. However, none of the previously discussed studies provide any strong evidence toward a clear cause-and-effect relationship. One possible explanation is that methanogenic organisms may favor proliferation in an environment of slower transit. This notion is supported by studies that have shown that treatment with laxatives and bowel cleanses can eliminate methane production in some patients. ${ }^{26,27}$

Taken together, abnormal intraluminal pressure has been implicated as pathogenetic factors in diverticulosis. Intraluminal pressure in the ascending colon of patients with right-colon diverticula was studied via catheter-tip transducers inserted during colonoscopy. ${ }^{30}$ They showed that high resting and prostigminestimulated intraluminal pressures were found in right-sided diverticular disease. Painter et $\mathrm{al}^{15}$ reported that non-propulsive segmental contractions of the colon could increase intraluminal pressure. Abnormal intraluminal pressure, the most common colonic motor pattern in tonic segmenting and rhythmic contractions, creates stationary narrow rings that appear as haustral markings. It was reported that the intermittent segmentation process of systematic contraction of the circular muscle divides the lumen into a series of compartments and, as a result, increases intracolonic pressure within these compartments led to the generation of diverticula. ${ }^{31}$

Based on above studies, we assumed that methane or hydrogen gas produced by enteric bacteria might play a role in development of right colonic diverticula because the gases might alter the colonic transit time contributing to non-propulsive segmental contraction, which might increase intraluminal pressure forming right colonic diverticula. However there was no statistically significant relation between development of right colonic diverticula and intestinal gas. Moreover, in diverticular group the patients with positive LBT did not have difference in bowel symptoms compared with others having negative LBT within the diverticular group.

And we expected the different composition of intestinal gases might have effects on diverticula by relatively high concentration of methane because the methanogens can significantly decrease the volume of hydrogen by combining hydrogen and carbon dioxide for their energy. ${ }^{32}$ But the ratio of methane to hydrogen was not also statistically different between the diverticular and control group.

One limitation of our study is that LBT only represented the concentration of breath methane and hydrogen gas at the study time. The formation of diverticula is a time-dependent process; our cross-sectional study with LBT could not show a correlation between methane or hydrogen concentration and the formation of diverticula. In this study, we only examined the concentration of breath methane and hydrogen gas at one occasion. We did not measure serial breath gases for a long enough time to properly evaluate this time-dependent process. Although methane gas could increase intraluminal pressure, increased pressure should be demonstrated to form diverticula over a sufficiently long period and then better conclusions could be drawn regarding the relationship between increased pressure and diverticula formation.

Moreover another limitation was that that right colonic diverticula occur in the childhood ${ }^{17}$ but this study was performed in the mean age of 47.4 (control group) and 53.3 (diverticular group), which could be one of cause of negative study. And this is a negative study involving a small number of subjects without a pretest power analysis. Thus, the possibility of a type II error exists and would prevent the drawing of a definitive conclusion. Therefore, long-term follow-up methods for evaluating effects of intestinal gas are needed to reveal the exact pathogenesis of right colonic diverticula.

\section{References}

1. Jun S, Stollman N. Epidemiology of diverticular disease. Best Pract Res Clin Gastroenterol 2002;16:529-542.

2. Painter NS, Burkitt DP. Diverticular disease of the colon: a deficiency disease of Western civilization. Br Med J 1971;2:450-454.

3. Commane DM, Arasaradnam RP, Mills S, Mathers JC, Bradburn $\mathrm{M}$. Diet, ageing and genetic factors in the pathogenesis of diverticular disease. World J Gastroenterol 2009;15:2479-2488.

4. Stephen AM, Wiggins HS, Englyst HN, Cole TJ, Wayman BJ, Cummings JH. The effect of age, sex and level of intake of dietary fibre from wheat on large-bowel function in thirty healthy subjects. $\mathrm{Br}$ J Nutr 1986;56:349-361.

5. Simpson J, Scholefield JH, Spiller RC. Pathogenesis of colonic diverticula. Br J Surg 2002;89:546-554.

6. Ohta M, Ishiguro S, Iwane $\mathrm{S}$, et al. An epidemiological study on relationship between intake of dietary fiber and colonic diseases. Nippon Shokakibyo Gakkai Zasshi 1985;82:51-57.

7. Stollman N, Raskin JB. Diverticular disease of the colon. Lancet 2004;363:631-639.

8. Young-Fadok TM, Roberts PL, Spencer MP, Wolff BG. Colonic diverticular disease. Curr Probl Surg 2000;37:457-514.

9. Touzios JG, Dozois EJ. Diverticulosis and acute diverticulitis. Gastroenterol Clin North Am 2009;38:513-525. 
10. Sugihara K. Diverticular disease of the colon in Japan. Ann Acad Med Singapore 1987;16:504-508.

11. Ye H, Losada M, West AB. Diverticulosis coli: update on a "Western" disease. Adv Anat Pathol 2005;12:74-80.

12. Flourie B, Etanchaud F, Florent C, Pellier P, Bouhnik Y, Rambaud JC. Comparative study of hydrogen and methane production in the human colon using caecal and faecal homogenates. Gut 1990;31: 684-685.

13. Sheth AA, Longo W, Floch MH. Diverticular disease and diverticulitis. Am J Gastroenterol 2008;103:1550-1556.

14. Painter NS, Burkitt DP. Diverticular disease of the colon, a 20th century problem. Clin Gastroenterol 1975;4:3-21.

15. Painter NS, Truelove SC, Ardran GM, Tuckey M. Segmentation and the localization of intraluminal pressure in the human colon, with special reference to the pathogenesis of colonic diverticula. Gastroenterology 1968;54(suppl):778-780.

16. Miura S, Kodaira S, Aoki H, Hosoda Y. Bilateral type diverticular disease of the colon. Int J Colorectal Dis 1996;11:71-75.

17. Sugihara K, Muto T, Morioka Y, Asano A, Yamamoto T. Diverticular disease of the colon in Japan. A review of 615 cases. Dis Colon Rectum 1984;27:531-537.

18. Markham NI, Li AK. Diverticulitis of the right colon - experience from Hong Kong. Gut 1992;33:547-549.

19. Stemmermann GN. Patterns of disease among Japanese living in Hawaii. Arch Environ Health 1970;20:266-273.

20. Weaver GA, Krause JA, Miller TL, Wolin MJ. Incidence of methanogenic bacteria in a sigmoidoscopy population: an association of methanogenic bacteria and diverticulosis. Gut 1986;27:698-704.

21. Chatterjee S, Park S, Low K, Kong Y, Pimentel M. The degree of breath methane production in IBS correlates with the severity of constipation. Am J Gastroenterol 2007;102:837-841.
22. Park HJ, Jahng JH, Lee SI. The effect of bowel gases produced by enteric bacteria on small bowel motility and colonic transit time of guinea pig. Neurogastroenterol Motil 2009;21:39.

23. Pimentel M, Lin HC, Enayati P, et al. Methane, a gas produced by enteric bacteria, slows intestinal transit and augments small intestinal contractile activity. Am J Physiol Gastrointest Liver Physiol 2006; 290:G1089-G1095.

24. Park $\mathrm{H}$. The role of small intestinal bacterial overgrowth in the pathophysiology of irritable bowel syndrome. J Neurogastroenterol Motil 2010;16:3-4.

25. McKay LF, Eastwood MA, Brydon WG. Methane excretion in man - a study of breath, flatus, and faeces. Gut 1985;26:69-74.

26. Peled Y, Weinberg D, Hallak A, Gilat T. Factors affecting methane production in humans. Gastrointestinal diseases and alterations of colonic flora. Dig Dis Sci 1987;32:267-271.

27. Fiedorek SC, Pumphrey CL, Casteel HB. Breath methane production in children with constipation and encopresis. J Pediatr Gastroenterol Nutr 1990;10:473-477.

28. Pimentel M, Mayer AG, Park S, Chow EJ, Hasan A, Kong Y. Methane production during lactulose breath test is associated with gastrointestinal disease presentation. Dig Dis Sci 2003;48:86-92.

29. Cloarec D, Bornet F, Gouilloud S, Barry JL, Salim B, Galmiche JP. Breath hydrogen response to lactulose in healthy subjects: relationship to methane producing status. Gut 1990;31:300-304.

30. Sugihara K, Muto T, Morioka Y. Motility study in right sided diverticular disease of the colon. Gut 1983;24:1130-1134.

31. Painter NS, Truelove SC. The Intraluminal Pressure Patterns in Diverticulosis of the Colon. I. Resting Patterns of Pressure. II. The Effect of Morphine. Gut 1964;5:201-213.

32. Strocchi A, Levitt MD. Maintaining intestinal $\mathrm{H} 2$ balance: credit the colonic bacteria. Gastroenterology 1992;102:1424-1426. 